\title{
PREFACE
}

\author{
Stuart Sim
}

\begin{abstract}
Why do so many critical theorists turn to science to find reinforcement for their theories? Can the cognitive sciences provide a new direction for critical theory? Can Marxism still contribute to theoretical debate after the fall of communism and the Soviet empire that was founded on it? Has postmodernism run its course and become a dead end? Is there any value left in structuralist principles? These are just some of the questions posed by this Companion, in which an international team of academic specialists on the topic considers the changing role of critical theory in the new century, demonstrating its continuing importance across disciplines ranging from the arts and social sciences through to the hard sciences, as well as the new directions, ideas and theorists emerging in each of the fields. Taking note of the many new theoretical and socio-political developments in recent years, the Companion provides readers with an opportunity to reorient themselves within the history and role of critical theory in its many forms.
\end{abstract}

\section{Structure and Format of the Companion}

The volume is divided into eleven sections comprising twenty-eight chapters overall, with each covering a particular branch of critical theory from Marxism through to present-day developments. Every chapter will consider the historical development of the theory in question, outlining the main concepts and thinkers involved, and then move on to assess its relevance to current academic and socio-political concerns and debates, paying particular attention to recent advances in the area and the emergence of new voices. The advent of poststructuralist and postmodern theory, for example, has led to a reassessment of the foundational bases of critical theories in general that is still very much ongoing. The changing fortunes of Marxism in the last few decades have had a dramatic impact on the entire field of critical theory, given its widespread influence as a body of thought throughout the twentieth century, that is still in process. Feminism continues to evolve, positioning itself 
against new developments in the field and generating many of these itself in turn. Cognitive science is opening up exciting possibilities for the creation of new lines of critical enquiry. Indeed science in general is doing so, as theories about the nature of the universe keep appearing and competing with each other for our attention. Few theorists can be unaffected by how this is altering our perspectives about the nature of human culture, science being the primary source of metaphysical ideas these days (appropriately enough, physics being the leading player). Even theories that have been around for a long time have not been immune from such changes, and the volume therefore will provide a comprehensive overview of all the main areas of critical theory to determine where they stand now in relation to these.

The book's sections comprise:

I) Marxism

II) Structuralism

III) Poststructuralism

IV) Postmodernism

V) Postcolonialism

VI) Gender

VII) Feminism

VIII) Historicism

IX) Formalism

X) Science and Critical Theory

XI) Psychoanalysis and Critical Theory.

Inevitably, there are often overlapping themes and concerns in these chapters, with theories and theorists appearing in a different perspective each time around to indicate the need to be aware of what is being discussed across the entire field. Theories are not produced in isolation, but within a dynamic context of debate, where ideas are constantly being tested, refined and extended. The volume's chapters cross-reference in such a way as to make this interactive quality of critical theory constantly apparent.

In each chapter, textual citation will be given briefly in brackets to the particular edition being used, with full publication details (including original publication dates for older texts) to be found in the master bibliography at the end of the book.

\section{The Scope and Range of Critical Theory}

Critical theories have proliferated over the course of the modern era and on into the postmodern, and are now extensively deployed in pretty well every area of intellectual enquiry. Academic life is all but unimaginable without critical theory, where it forms the basis of textual interpretation and discourse 
construction - as it notably does in such areas as literary studies, media studies, philosophy, sociology and politics. Theories come and go, however, and their fortunes can fluctuate markedly according to the fashion of the age. Structuralism can become one of the leading methods for a few decades from the mid-twentieth century onwards and then decline sharply in popularity after the rise of poststructuralism. Feminism keeps branching out in new directions, each with its own set of concerns that can to some extent supersede older versions of the theory: the 'second wave' challenging many of the assumptions and goals of the 'first wave', for example, and now a 'third wave' of postfeminism making its mark in the discourse as well.

New theories keep emerging as science progresses and the socio-political landscape changes. Equally, older theories can be adapted to current developments and continue to have an impact on debate, rather than just remaining as historical curiosities - the fate, for example, of most older scientific theories. Despite the critiques put forward by poststructuralists, and these are by no means accepted by all other theorists, there are still insights to be yielded by structuralism. Structure is always a critical factor in the analysis of narratives taking the word 'narrative' in its broadest sense, as Roland Barthes does when he declares that ' $[t]$ he narratives of the world are numberless' (Barthes 1977: 79). New Criticism is still a useful teaching tool to help students of literary studies understand the inner design, and the effect it can make on readers, of texts, particularly poetic texts.

\section{Applying Critical Theory}

Critical theory tends to be used in a fairly eclectic manner these days, with elements of various theories often being combined in the art of analysis. A synthetic approach is probably now the norm, with textual analysts each putting together their own model, drawing freely on the range of theories available to them. That is one of the key reasons to be aware of what the field as a whole has to offer us. It is inconceivable to engage with any field in the humanities and social sciences (and increasingly, even the hard sciences), without the facility of critical theory with which to position yourself against existing interpretations and construct your own in turn. Once you construct a reading of a text, then you enter into the wider critical debate, and are contributing to how the field is developing. Being theoretically informed is not an optional part of study any more; it is instead a necessary, central, part. This volume is designed to bring you up to date with what is happening right across the spectrum of critical theory, so that you can become a part of that wider debate.

\section{The Future of Critical Theory}

There has been speculation of late that we have reached the 'end' of theory, that its 'moment' has now passed and it is now of no more than historical 
interest - conferences even get held on this issue. In the sense of so-called 'high theory' and the academically divisive 'theory wars' that it spawned back in the 1980s and 90s, when new 'isms' seemed to be coming on stream with bewildering rapidity, that is probably the case. It is not likely that theories of society will cease to be devised, however, and these cannot avoid having implications for all aspects of society, including criticism and cultural commentary in general. Neither can textual interpretation avoid projecting a world view that will relate to a particular social theory, even if only implicitly, giving it an ideological significance: in that respect, no interpretation can be apolitical. Texts, of all kinds, will continue to be reinterpreted by each new generation, and to acquire different meanings within a changing society. That is the task of critical theory, and the more we are aware of its history, then the more resonant our textual interpretations will become within society at large. 